\title{
Brueghel Syndrome as a New Manifestation of HIV Encephalopathy
}

\author{
Jacques Wicki ${ }^{a}$ Yves Germanier ${ }^{\mathrm{a}} \quad$ Roman Sztajzel $^{\mathrm{b}} \quad$ Pierre R. Burkhard $^{\mathrm{b}}$ \\ Departments of ${ }^{\mathrm{a}}$ Internal Medicine, and ${ }^{\mathrm{b}}$ Neurology, Geneva University Hospitals and Faculty of Medicine, \\ Geneva, Switzerland
}

\begin{abstract}
Dear Sir,
A large variety of movement disorders have been reported in HIV-infected patients including tremor, hemichoreahemiballism, paroxysmal dyskinesia, tic, myoclonus, dystonia, and parkinsonism [1-4]. In most cases, hyperkinesias have been related to AIDS-defining opportunistic infections involving the basal ganglia, in particular toxoplasmosis, whereas parkinsonism and tremor have been linked to a deleterious effect of HIV-related pathology on the dopaminergic system $[1,3]$. Only a few patients with focal or generalized dystonia have been reported so far [2, 4-8], only one of them possibly related to HIV infection itself [5]. We here report a unique patient who rapidly developed a severe blepharospasm-oromandibular dystonia syndrome corresponding to Brueghel syndrome as the revealing manifestation of HIV encephalopathy, which entirely resolved when treated by highly active antiretroviral therapy (HAART).
\end{abstract}

\section{Case Report}

A 44-year-old white woman was admitted to our institution for a 2-week history of progressive apathy and paraparesis. She was known for intravenous drug and alcohol abuse, and a 5-year untreated HIV infection. General examination was unremarkable except for frequent episodes of hyperpnea. Mental status was severely altered and characterized by severe cognitive slowing, disorientation to time and place and fluctuating somnolence. The most striking feature involved facial abnormal involuntary movements consisting of a complex, bilateral and constantly evolving facial dystonia which included, either successively or simultaneously, frowning, blepharospasm, eyelid-opening apraxia, contractions of paranasal muscles and lips reminiscent of rabbit syndrome, and multidirectional movements of the jaw with frequent wide opening of the mouth (fig. 1a). These movements led to a dramatic and continuous facial grimacing which worsened when the patient was stimulated and disappeared during sleep. In addition, she exhibited diffuse spasticity, hyperreflexia, bilateral Babinski sign, urinary incontinence and incomplete paraplegia.

Blood tests showed marked pancytopenia and liver dysfunction. HIV staging was C3 with a low CD4 count (CD4 16/ $\mathrm{mm}^{3}$, normal $600-1,950 / \mathrm{mm}^{3}$ ) and high viremia $(600,000$ copies $/ \mathrm{ml})$. Brain magnetic resonance imaging (MRI) scan showed, on $\mathrm{T}_{2}$ weighted and FLAIR images, confluent hyperintensities involving the lenticular nucleus bilaterally, particularly prominent in the left globus pallidus and extending toward internal capsules (fig. 1c, d). Cerebrospinal fluid analyses were normal except for mildly elevated total proteins ( 0.68 $\mathrm{g} / \mathrm{l})$. EEG demonstrated generalized slow dysrythmia. An extensive search for opportunistic infections proved negative, $\mathrm{HCV}$ antibodies were positive. HIV encephalopathy was diagnosed and HAART associating lamivudin $300 \mathrm{mg} / \mathrm{day}$, zido- vudin $600 \mathrm{mg} /$ day and efavirenz $600 \mathrm{mg} /$ day was initiated. Evolution was rapidly favorable already after a few days thereafter and both facial dystonia and paraplegia completely resolved within 2 months (fig. 1b). A repeated MRI scan demonstrated a nearly complete resolution of basal ganglia abnormalities.

\section{Discussion}

This HIV-infected patient exhibited a severe facial dystonia whose characteristics are typical of Brueghel syndrome, an eponimic entity that has been proposed by Marsden in 1976 to describe a particular subset of cranial adult-onset torsion dystonia associating blepharospasm and oromandibular dystonia with particular emphasis on spasmodic jaw opening [9]. Gilbert further underlined features distinguishing Brueghel from Meige syndrome, in particular a dystonically opened mouth accompanied by paroxysmal hyperpnea episodes [10]. Not only had our patient these typical features, but she also exhibited additional signs such as rabbit syndrome and eyelid-opening apraxia. Brueghel syndrome has been only rarely reported in the literature [9-12] and most cases, similarly to Meige syndrome, have been considered idiopathic, no specific lesion site being consistently demonstrated, although a basal ganglia dysfunction or brain stem lesions have long been suspected $[9,10]$.

\section{KARGER}

Fax +4161306 1234 E-Mail karger@karger.ch www.karger.com
Pierre R. Burkhard, MD

Department of Neurology

Geneva University Hospitals

$\mathrm{CH}-1211$ Geneva 14 (Switzerland)

Tel. +41 2237283 09, Fax +41 2237283 32, E-Mail Pierre.Burkhard@hcuge.ch 

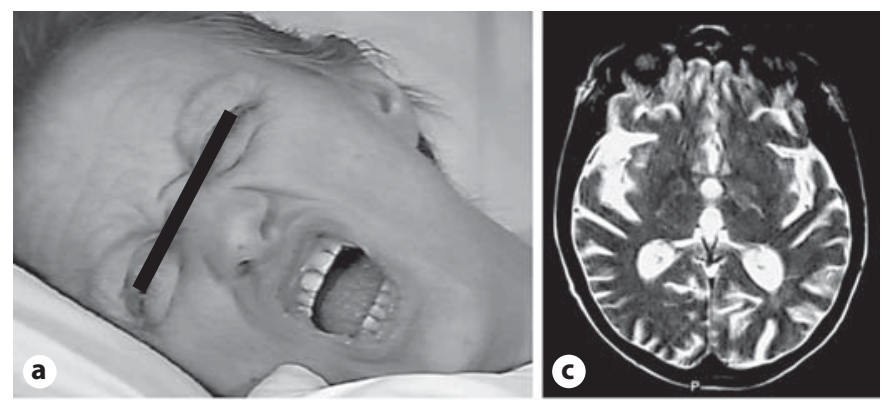

Fig. 1. a The reported patient's face a few days after hospitalization, exemplifying the typical aspect of Brueghel syndrome including blepharospasm and jaw-opening dystonia. b The same patient 2 months later after she has been successfully treated with HAART. c, d Brain MRI scan images at the level of the basal ganglia showing, on a $\mathrm{T}_{2}$-weighted axial slice (c) and a FLAIR coronal slice (d), confluent and bilateral hyperintensities involving both lenticular nuclei, more markedly the left globus pallidus, as MRI abnormalities related to florid HIV encephalopathy.
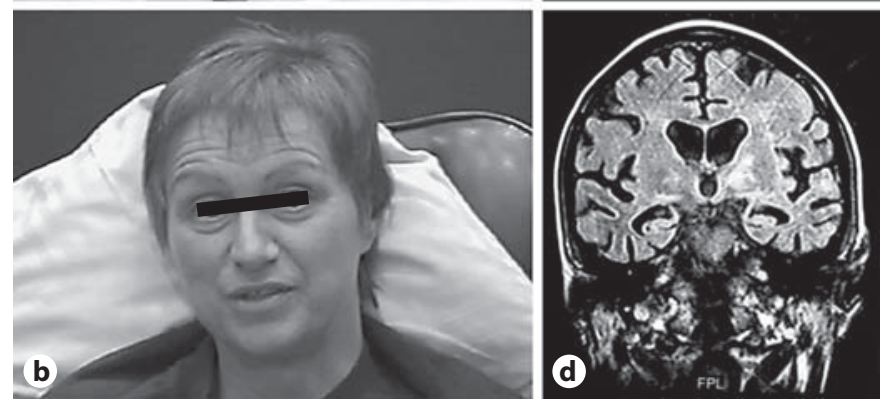

In this setting, our patient appears unique by many aspects. First, facial dystonia as the presenting manifestation of HIV encephalopathy has, to the best of our knowledge, not been reported yet, and this case may be considered another example of a highly unusual mode of presentation of HIV encephalopathy and added to the already long list of neurological manifestations of HIV infection. Second, despite its initial severity and spectacular manifestation, Brueghel syndrome - and related neuromaging abnormalities - proved entirely reversible when specifically treated with HAART, further supporting HIV itself as the only causal factor underlying this focal dystonia. It must be underlined that the patient never received any dopamine receptor blocker, for example. Finally, and perhaps more importantly, this case demonstrates an undisputable relationship between bilateral pallidal lesions and the development of the facial dystonia, the more so as there was no other MRI abnormality elsewhere in the brain, notably no brain stem lesion. Thus, this case provides further support to the hypothesis of altered basal ganglia being central for Brueghel syndrome, and perhaps other facial dystonias, to manifest.

\section{References}

1 Tse W, Cersosimo MG, Gracies JM, Morgello S, Olanow CW, Koller W: Movement disorders and AIDS: a review. Parkinson Relat Disord 2004;10:323-334.

2 Mattos JP, Rosso AL, Correa RB, Novis SA: Movement disorders in $28 \mathrm{HIV}$-infected patients. Arqu Neuropsichiatr 2002;60:525530.

$\checkmark 3$ Cardoso F: HIV-related movement disorders: epidemiology, pathogenesis and management. CNS Drugs 2002;16:663-668.

-4 Nath A, Jankovic J, Pettigrew LC: Movement disorders and AIDS. Neurology 1987;37:3741.

-5 Abbruzzese G, Rizzo F, Dall'Agata D, et al: Generalized dystonia with bilateral striatal computed-tomographic lucencies in a patient with human immunodeficiency virus infection. Eur Neurol 1990;30:271-273.
6 Tolge CF, Factor SA: Focal dystonia secondary to cerebral toxoplasmosis in a patient with acquired immune deficiency syndrome. Mov Disord 1991;6:69-72.

7 Vielhauer V, Schewe CK, Schlondorff D: Bilateral thrombosis of the internal jugular veins with spasmodic torticollis in a patient with acquired immunodeficiency syndrome and disseminated cytomegalovirus infection. J Infect 1998;37:90-91.

8 Factor SA, Troche-Panetto M, Weaver SA: Dystonia in AIDS: report of four cases. Mov Disord 2003;18:1492-1498.

-9 Marsden CD: Blepharospasm-oromandibular dystonia syndrome (Brueghel's syndrome). A variant of adult-onset torsion dystonia ? J Neurol Neurosurg Psychiatry 1976; 39:1204-1209.

10 Gilbert GJ: Brueghel syndrome: its distinction from Meige syndrome. Neurology 1996; 46:1767-1769.

-11 Garcia-Albea E, Franch O, Munoz D, Ricoy JR: Brueghel's syndrome, report of a case with postmortem studies. J Neurol Neurosurg Psychiatry 1981;44:437-440.

-12 Miyaoka T, Miura S, Seno H, Inagaki T, Horiguchi J: Jaw-opening dystonia (Brueghel's syndrome) associated with cavum septi pellucidi and Verga's ventricle - a case report. Eur J Neurol 2003;10:727-729. 